\title{
The role of micro cavitation on EHL: a study using a multiscale mass conserving approach
}

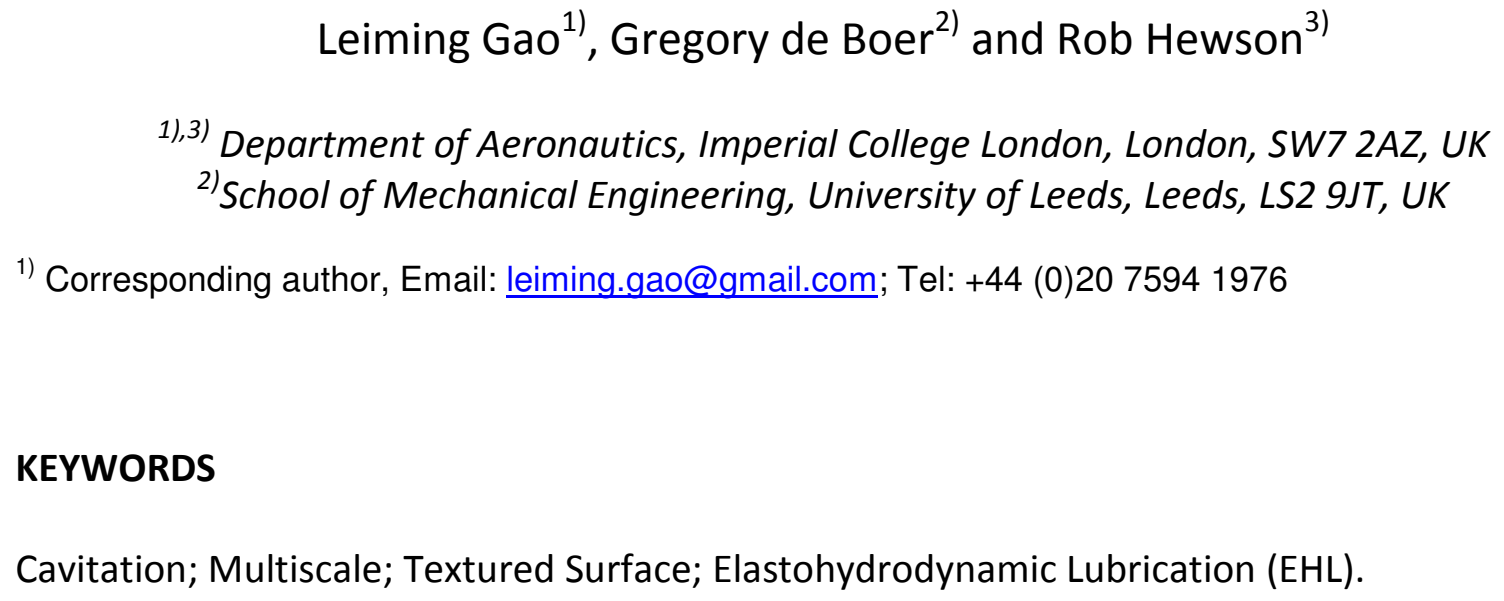

\section{KEYWORDS}

Cavitation; Multiscale; Textured Surface; Elastohydrodynamic Lubrication (EHL).

\begin{abstract}
The role of micro cavitation in Elastohydrodynamic Lubrication is numerically investigated using a multiscale approach whereby both the small scale topographical features and the micro-cavitation of the lubricant due to the features are resolved. Micro-cavitation and the fluid's shear-thinning property are modelled at the small scale of topological feature. The effects of topographical features on the film thickness of the line contact bearings and friction coefficient are presented with a focus on the role of micro-cavitation. This highlights how a mass conserving small scale model can be used to model both micro-cavitation and cavitation occurring at the bearing scale, and how topological features can be designed to reduce friction while maintaining bearing load.
\end{abstract}




\section{INTRODUCTION}

In this paper the role of cavitation in an Elastodhydrodynamic Lubrication (EHL) convergingdiverging line contact is investigated. The bearing surfaces are a smooth moving roller surface relative to a stationary, textured flat surface. Topographical changes to a lubricated surface of industrial components have been experimentally and numerically shown to improve their tribological performance in three main aspects, the load carrying capacity, the friction coefficient and the lubricant fluid film 1, 2. Such applications include piston rings 3,4 , mechanical seals 5, 6, journal bearings 7, 8, pad bearings 9-12, and roller bearings in line contacts 13-17 and point contacts 18, 19.

A number of numerical approaches have been proposed to represent lubrication of surfaces with topographical features $7,[17,18,20,21$. One of the challenges of numerically describing these problems is the order of magnitudes difference in the size of bearing surface topography and the bearing itself. This has led to a number of multiscale methodologies to analyse the problem and overcome the limitation in terms of computing costs 22-26. Among the multiscale models, many of them employ an adapted Reynolds equation based on Patir and Cheng's average flow model 27. to solve the large scale fluid pressure, and the Stokes or Navier-Stokes equations to solve the small scale fluid flow 22, 24, 26. Recently, the homogeneous multiscale approach has been developed, in which the large scale fluid flow was governed by a homogeneous pressure-gradient function whose coefficient was obtained from the small scale simulations. These include the work of Nyemeck et al. 25 on the hydrodynamic lubrication with rigid bearing surfaces of seals, and the authors' work [11, 12 , on the EHL simulation of micro-textured pad bearings.

The role of micro-cavitation on lubrication has been studied by a number of investigators arising from experimental observation of cavitation occurring in the vicinity of surface roughness 20, 28. The role of cavitation raises further questions regarding the validity of using a form of the lubrication equation, where cavitation effects may not be uniform across the film thickness due to the underlying topography; this cannot be captured by the lubrication approximation where a constant pressure is assumed across the film thickness. Olver et al. 29 . proposed an 'inlet suction' effect due to fluid flow driven by cavitation pressures located in the 
1 inlet region of the pad bearing surface. Ausas et al. 30. and Qiu and Khonsari et al. 31 . studied micro-cavitation in textured bearing lubrication using a mass conserving model and compared different boundary conditions of cavitation; the half-Sommerfield condition, SwiftSteiber (Reynolds) condition and the Floberg-Jakobsson-Olsson (JFO) condition. It was found that the Reynolds condition largely underestimated the cavitation area and predicted a higher load-carrying capacity than the JFO results. Other studies of micro-cavitation have used NavierStokes based Computational Fluid Dynamics (CFD) simulations to solve the fluid flow, for example, Shi and $\mathrm{Ni}$ 32, Wahl et al. 33. and Meng and Yang 34. However, these studies of micro-cavitation were all modelled at a single scale, where the topographical features were described over the entire lubrication domain. The number of simulated micro dimples or grooves in these studies was limited to up to 10 due to the very fine mesh required to resolve the small scale features and cavitation. In real engineering applications the number of micro dimples (and roughness) could be much larger on a real textured bearing's surface, and a multiscale method is especially relevant to solve such problem.

In this paper the heterogenous multiscale method (HMM) 35 is applied to EHL as derived by the authors $11,12,36$ and extended to include cavitation effects, via the application of a mass-conserving approach at both small and large scales. This enables the model to capture cavitation at both scales. The pressure gradient-mass flow rate relationship is obtained from a homogenised local scale solution. This relationship is subsequently used at the global scale as a governing equation of fluid flow, and solved along with the conservation of mass. In this work cavitation is considered at the local scale via a predefined threshold cavitation pressure. The effects of the micro-texture's geometrical parameters on the bearings' lubrication film thickness and friction coefficient are presented. The piezo-viscous and shear-thinning effects are discussed and the importance of the role of micro cavitation at the small scale is highlighted.

\section{NUMERICAL METHODOLOGY}

\subsection{Geometry and Materials}


In this study, the global geometry of the lubrication model is a two-dimensional cylindrical line contact. The smooth cylinder rotates relative to a textured stationary surface, as shown in

together with the mass conservation equation

$$
\frac{d \dot{m}}{d x}=0
$$

17 The pressure gradient $\left(\frac{d \hat{p}}{d x}\right)$ is a homogenised function of the pressure $(\hat{p})$, mass flow rate $(\dot{m})$ and film gap $(g)$, interpolated from a series of small scale solutions. The large scale boundary conditions used to solve Eqs. (1) and 2, are that the pressure at the bearing inlet and outlet boundaries is equal to zero:

$$
\hat{p}_{\text {in }}=\hat{p}_{\text {out }}=0
$$

21 The line contact bearing load is balanced by an integral of the average small scale pressure (i.e., load per unit length $p^{*}$ ), along the line contact domain. The average small scale pressure $\left(p^{*}\right)$ was defined in Eq. 17 ) in the Section 2.3.1 'Small Scale Simulations'.

$$
w=\int_{\text {xin }}^{x o u t} p^{*} d x
$$


1 The geometry equation is expressed as a sum of the rigid displacement ( $e$, an unknown constant determined by load $w$ ), rigid gap geometry and the surface deformation $(\delta)$ :

$$
\begin{gathered}
h=e+\frac{x^{2}}{2 r}+\delta \\
\delta=\boldsymbol{K} \times p^{*}
\end{gathered}
$$

3 where the displacement influence coefficient matrix $\boldsymbol{K}$ was obtained using the Green's function 437 for linear elastic contact model.

\subsection{Small Scale Simulations}

The small scale problem is described by the flow equations and those governing the elastic deformation of the small scale features. The coupling is facilitated through the application of the Arbitrary Largrangian Eularian (ALE) method to describe the fluid domain as the solid domain deforms and the inclusion of non-Newtonian, piezo-viscous and cavitation effects are included.

\subsubsection{Solid Structure Model}

The small scale solid domain is described by a plain strain model with the separation of the displacement influence coefficient matrix $\boldsymbol{K}$ into local (diagonal, $\boldsymbol{K}_{1}$ ) and global (off-diagonal, $\left.\boldsymbol{K}_{2}\right)$ terms 12. The film gap $(g)$ at the small scale is described by the sum of undeformed gap and the non-local deformation $\left(\boldsymbol{K}_{2} \times p\right)$, not including the local deformation $\left(\boldsymbol{K}_{1} \times p\right)$.

$$
g=e+\frac{x^{2}}{2 r}+K_{2} \times p
$$

The local terms are represented as part of the local fluid-structure interaction simulation, and the global terms are applied as they would be in a conventional EHL simulation. An equivalent height of the solid domain is introduced in order to ensure that the local deformation in the small scale simulations is the same as the column deformation obtained from the diagonal matrix. For further details of the structure model the reader is referred to references 12 .

\subsubsection{Laminar Flow Model}


The steady-state, isothermal and laminar flow is governed by the compressible NavierStokes equations:

$$
\begin{gathered}
\rho(\mathbf{u} \cdot \nabla) \mathbf{u}=\nabla \cdot\left[-p \mathbf{I}+\eta\left(\nabla \mathbf{u}+(\nabla \mathbf{u})^{\mathrm{T}}\right)-2 \eta / 3(\nabla \cdot \mathbf{u}) \mathbf{I}\right] \\
\nabla \cdot(\rho \mathbf{u})=0
\end{gathered}
$$

3 where, $\mathbf{u}$ is the fluid velocity vector and $\mathbf{I}$ the unit tensor. $\rho$ is the generalized fluid density

4 which is a function of pressure based on Dowson-Higginson formula 38,

$$
\rho=\theta \cdot \rho_{0} \frac{c_{1}+c_{2} \cdot p}{c_{1}+p}
$$

5 where, $c_{1}$ and $c_{2}$ are the density-pressure coefficients, $\rho_{0}$ is the density at ambient pressure, $\theta$

6 is the density fraction of liquid in the liquid and gas mixture and is defined in the cavitation 7 model in Section 2.3.2. Piezo-viscous effects are described by an exponential relationship 39 , 8 the viscosity of liquid and gas mixture $(\eta)$ is expressed as:

$$
\eta=\theta \cdot \eta^{*} \exp (\alpha \cdot p)
$$

9 with the pressure-viscosity coefficient $\alpha$. Considering the fluid shear-thinning property, the generalized viscosity $\eta^{*}$ is defined using a Carreau viscosity model 40 below.

$$
\eta^{*}=\eta_{\infty}+\left(\eta_{0}-\eta_{\infty}\right)\left[1+\left(\eta_{0} \dot{\gamma} / G_{c r}\right)^{2}\right]^{\frac{m-1}{2}}
$$

11 where, $\dot{\gamma}$ is shear rate. $\eta_{0}$ and $\eta_{\infty}$ represent the dynamic viscosity at zero shear rate and 12 infinite shear rate, respectively. $G_{c r}$ is critical stress at ambient pressure. The piezo-viscous 13 effect described in Eq. (11) and the shear-thinning property defined in Eq. 12) are illustrated in 14 Fig. 2.

The boundary conditions are shown in Fig. 1b. The lower boundary CD (Fig. 1b) is a sliding wall. The upper fluid-structure interface is a no slip boundary. In heterogenous multiscale method, periodic boundary conditions are required on the $A D$ and $B C$ boundary in terms of fluid velocity and pressure. Due to small scale deformation the two boundary geometries are not exactly the same, therefore, the boundary BC was scaled to the same length of boundary $A D$ in the reference coordinates (undeformed gap) 12. Near-periodic velocity boundary conditions are derived from the mass conservation at the two boundaries, scaled by the local strain $\varepsilon$ :

$$
\rho_{1} \boldsymbol{u}_{1}\left(1+\varepsilon_{1}\right)=\rho_{2} \boldsymbol{u}_{2}\left(1+\varepsilon_{2}\right)
$$


1 and a pressure jump $(\Delta p)$ is applied onto the scaled boundaries:

$$
p_{2}=p_{1}+\Delta p
$$

2 where, subscript 1 and 2 represent the scaled boundary $A D$ and $B C$ in Fig. $1 b$ respectively. Since 3 the moving wall (lower surface) was fully constrained, i.e. there was no deformation allowed 4 and the strain was zero, the velocities at both sides of the fluid domain on the moving wall 5 surface were the same. Thus the nearly periodic conditions described in Eq. (Error! Reference source not found.) are the same as periodic conditions at the moving surface and it satisfies

7 the no-slip boundary conditions.

8 The homogenised pressure gradient $\left(\frac{d \hat{p}}{d x}\right)$ across a unit cell and a pressure jump across the small 9 scale cell is described by:

$$
\frac{d \hat{p}}{d x}=\frac{\Delta p}{L}
$$

10 The mass flow rate $(\dot{m})$ is calculated as:

$$
\dot{m}=\int_{0}^{g+K_{1} \times p} \rho u d y
$$

11 An average pressure $\left(p^{*}\right)$ is defined to represent the cell pressure in large scale solutions:

$$
p^{*}=\int_{0}^{L} p d x / L
$$

12 The shear stress $\tau$ (shear force per unit length) is calculated as:

$$
\tau=\int_{0}^{L} \eta^{*} \frac{d u}{d y} d x / L
$$

13

\subsubsection{Cavitation Model}

The lubricant is assumed to be a homogeneous mixture of liquid and gas. When the fluid pressure drops below the saturation pressure cavitation occurs and some gas dissolved in fluid will come out of solution. The density fraction of liquid $(\theta)$ is defined as a continuous function of pressure using the hyperbolic tangent function:

$$
\theta=0.5 \times\left(1+\tanh \frac{p-p_{c}}{k}\right)
$$


1 The constants $k$ are used to determine the steep gradient of the density fraction with respect 2 to a threshold cavitation pressure $p_{c}=-30 \mathrm{KPa}$. The variation of $\theta$ against pressure is shown

3 in Fig. 3. The relationship described here is similar to the polynomial based approach used by 4 Almqvist and Larsson 41, to describe the density of lubricant with the fluid pressure. The parameters of fluid properties are given in Table 2, and are based on mineral oil of the type typically used as bearing lubricant 42,43 .

\subsection{Homogenisation of the pressure gradient equation}

The homogenised relationship between the pressure gradient and mass flow rate links the small scale and large scale simulations. This relationship is obtained via interpolation. In order to obtain an accurate representation of the small scale model, a range of small scale

simulations were undertaken for a range of gaps $(g)$, homogenised pressure gradients $\left(\frac{\Delta p}{L}\right)$ and cell inlet pressures $\left(p_{1}\right)$. A linear interpolation function was adopted, based on a Delaunay triangulation of the data using Quickhull algorithm as implemented in Matlab 44. To obtain effective data samples for the interpolation, the range of input parameters are selected as shown in Table 3 with total number of 3000 sample points, based on the corresponding results of the smooth surface case of Reynolds equation.

Small scale solutions were obtained using the finite element method as implemented in COMSOL Multiphysics. The variables are transformed to the non-dimensional forms for convenience of numerical computing, for the global scale,

$$
X, Y=x, y / R_{H z}, G=\frac{g}{L}, \hat{P}=\frac{\hat{p} L}{\eta_{0} U_{0}}, \frac{d \hat{P}}{d X}=\frac{d \hat{p}}{d x} \cdot \frac{L^{2}}{\eta_{0} U_{0}}, \dot{M}=\frac{\dot{m}}{\rho_{0} U_{0} L}
$$

23 and for the small scale,

$$
P_{1}=\frac{p_{1} L}{\eta_{0} U_{0}}
$$

where $R_{\mathrm{Hz}}$ is the Hertzian contact radius, 


$$
R_{H z}=\sqrt{\frac{8 w r}{\pi E^{\prime}}}
$$

1 Subsequently, the pressure gradient equation is obtained via linear interpolation,

$$
\frac{d \hat{P}}{d X}(i)=f\left[P_{1}, G, \dot{M}, \frac{d \hat{P}}{d X}, \hat{P}(i), G(i), \dot{M}\right], i=1, \ldots, n
$$

2 where the first four parameters on the right-hand side $\left(P_{1}, G, \dot{M}, \frac{d \hat{P}}{d X}\right)$ were known and obtained 3 from small scale analysis. $n$ denotes the mesh points at the large scale domain. The non4 dimensional mass conservation equation is expressed as,

$$
\frac{d \dot{M}}{d X}(i)=0,, i=1, \ldots, n
$$

5

6

\section{Results}

A non-dimensional large scale domain of $X=[-4,2]$ and a fixed load of $2500 \mathrm{~N}$ was considered in this study. Large scale mesh independence tests were undertaken from 60 to 960 points in the large scale domain. For the Newtonian case with a smooth surface, the relative errors in the large-scale pressure and mass flow rate using different mesh are presented in Fig.4 (a), and the large-scale pressure distributions are compared in Fig.4 (b) and (c). The presence of smooth surface solutions allowed comparison with the solution obtained using 4 Reynolds equation. In current study the number of mesh nodes $n$ was set at 120, at which level 5 the relative errors were approximately $7 \%$ and $5 \%$ in pressure and mass flow rate respectively. 6 Four fluid viscosity models were investigated, i.e. (i) Newtonian, (ii) Newtonian and piezo1 viscous, (iii) shear-thinning, and (iv) both piezo-viscous and shear-thinning. In each model, a 8 range of cell lengths $(L=20,50$ and $100 \mu \mathrm{m})$ and depths $(d=0 \sim 30 \mu \mathrm{m}$, increased by $5 \mu \mathrm{m})$ 9 were considered. The friction coefficient and minimum film thickness are presented in Fig. 5. 20 Typical results showing how cavitation is captured at the large scale is shown in Fig. 6 (a) and (b) for the case of $L=100 \mu \mathrm{m}$ and $d=30 \mu \mathrm{m}$, where the large scale homogenised pressure and 2 viscosity are presented from the small scale simulations, and the elastic deformation of the bearing surface also presented. The development of cavitation at small scale is demonstrated 
1 in Fig. 6 (c) and (d), in the large scale outlet zone in the region of $X=[0.8,1.8]$. The role of shear thinning fluid properties is demonstrated in Fig. 7, where the homogenised viscosity is clearly observed to decrease in the main loading domain at the large scale. The combination of both piezo-viscosity and shear-thinning effect on the pressure, viscosity and film thickness is shown in Fig. 8.

\section{Discussion}

\subsection{Fluid Rheology}

It can clearly been seen from these results that through the careful selection of small scale depth and length, that the friction coefficient can be reduced. The friction coefficient is presented as a function of the depth to length ratio $(d / L)$ in Fig. 5 , these results imply that there is an optimal cell depth and length to achieve minimum friction. For example, in the Newtonian cases, for the cell length $L=50 \mu \mathrm{m}$ the minimum friction coefficient was observed with the cell depth $d=10 \mu \mathrm{m}$ and the reduction in the friction coefficient is $42 \%$ compared to the smooth surface; for the cell length $L=100 \mu \mathrm{m}$ the friction coefficient is reduced by $52 \%$ when the cell depth $d$ is $15 \mu \mathrm{m}$. This is similar to the results previously obtained by Gao and Hewson 36. who obtained a similar trend for a slider bearing with the same small scale surface features. In these cases there was a monotonic decrease in the friction with increasing small scale length to depth ratio $(d / L)$. What is interesting to note is that contrary to the previous case there is a clear minimum friction coefficient predicted for a cell depth to length ratio of around 0.15 for the cases of $L \geq 50 \mu \mathrm{m}$. In the previous case it was observed that the friction coefficient decreased then plateaued out to a near constant friction coefficient with increasing cell depth.

While the different fluid rheologies considered all exhibit similar characteristics it should be noted that the reduction in friction is most pronounced for the shear thinning fluid characteristics, where there is a 3 fold decrease in the friction coefficient for the largest cell geometry $\mathrm{L}=100 \mu \mathrm{m}$. The effect of piezo-viscous is not significant for a low pressure values encountered in the current study. The variations in the pressure, viscosity and film thickness 
1 are less than $10 \%$ by comparing the results with or without piezo-viscous effect considered, as shown in Figs. 7 and 8.

The minimum film thickness decreases with increasing cell depth as shown in Fig. 5, and this

4 has been reported in other EHL studies of textured surface 18, 20, 45. Examining the minimum film thickness shows how there is a clear compromise to be made between reducing friction and maintaining a reasonable fluid film, as the effect of topography is to reduce the minimum film thickness, with the greatest effect observed for the shear thinning fluid model. The reasonable fluid film should have a minimum value which is double or triple the surface roughness, i.e. the lambda ratio is 2 or 3 , which means the bearing could operate in the mixed or full film lubrication regime.

\subsection{Micro-Cavitation}

Cavitation was included in the small scale geometry, permitting the modelling of the converging-diverging geometry to be modelled without a specific large scale treatment of cavitation. The pressure distributed over the whole lubrication domain was governed by the homogenised pressure equation. This is different from classical EHL models, where the Reynolds boundary condition (pressure is positive everywhere) is commonly applied in the diverging geometry. Since the small scale pocket itself is a divergent-convergent geometry, the local pressure usually decreases at the inlet divergent edge, and then increase at the outlet convergent edge. When there is limited cavitation in the small scale the local pressure distributed is nearly anti-symmetrically (as shown by the top curve in Fig. 6 (c), at location $X=$ 0.8). When cavitation extended towards outlet zone, i.e. $X$ increases, the pressure field diverges from this. The cavitation region can be observed in Fig. 6 (d) where the region of low density fraction indicates a larger cavitated zone as $X$ increases. As the region of cavitation increases further the local pressure became nearly constant of $-30 \mathrm{KPa}$ (as shown by the bottom curve in Fig. 6 (c), at location $X=1.8)$.

What is interesting is that there is a rise in viscosity in the diverging region before cavitation occurs as shown in Fig. 7. This can also be observed when piezo-viscosity is also added to the model as is shown in Fig. 8. 


\section{CONCLUSION}

A heterogeneous multiscale model has been developed for the fluid-structure interaction in cylindrical line contact EHL with the bearing surface topography addressed. Fluid cavitation is explicitly modelled at the small scale via a continuous function of the fluid density and viscosity with pressure. The small scale cavitation effects are passed to the large scale model via the homogenised small scale relationship without further large scale treatment of cavitation. Such an approach also allows a range of rheological models to also be considered. The shearthinning effects have been found to have significant effect on the bearing performance as well as the optimum small scale features required for optimum performance.

\section{ACKNOWLEDGEMENT}

13 The authors would like to thank the Engineering and Physical Sciences Research Council

14 (Grant number EP/I103733/1) and the Leverhulme Trust (Grant number F/10 100/B) for the

15 financial support to this work.

\section{NOMENCLATURE}

18

\begin{tabular}{|l|l|}
\hline$d$ & Cell depth [m] \\
\hline$E$ & Young's modulus [Pa] \\
\hline$E^{\prime}$ & Equivalent Young's modulus [Pa] \\
\hline$e$ & Rigid displacement [m] \\
\hline$h$ & Large scale film thickness [m] \\
\hline$g$ & locally undeformed gap [m] \\
\hline $\mathbf{K}$ & Displacement influence coefficient matrix $\left[\mathrm{m}^{3} / \mathrm{N}\right]$ \\
\hline$L$ & Cell length [m] \\
\hline$n$ & Number of large-scale mesh grid \\
\hline$p$ & Pressure [Pa] \\
\hline$p_{c}$ & Threshold cavitation pressure $[\mathrm{Pa}]$ \\
\hline$\dot{m}$ & Mass flow rate per unit length $[\mathrm{kg} / \mathrm{m} / \mathrm{s}]$ \\
\hline$r$ & Radius of cylinder [m] \\
\hline$t^{\prime}$ & Equivalent small-scale cell height $[\mathrm{m}]$ \\
\hline $\mathrm{U}_{0}$ & Sliding speed of the roller $[\mathrm{m} / \mathrm{s}]$ \\
\hline
\end{tabular}




\begin{tabular}{|l|l|}
\hline$u$ & Fluid velocity vector $[\mathrm{m} / \mathrm{s}]$ \\
\hline$w$ & One-dimensional load per unit length $[\mathrm{N} / \mathrm{m}]$ \\
\hline$x$ & Coordinate in direction of fluid flow $[\mathrm{m}]$ \\
\hline$X$ & Dimensionless coordinate of $x$ \\
\hline$\alpha$ & Pressure-viscosity coefficient \\
\hline$\dot{\gamma}$ & Shear rate $[1 / \mathrm{s}]$ \\
\hline$\delta$ & Elastic deformation $[\mathrm{m}]$ \\
\hline$\varepsilon$ & Strain \\
\hline$\eta_{0}$ & Viscosity at zero shear rate $[\mathrm{Pa} \mathrm{s}]$ \\
\hline$\eta_{\infty}$ & Viscosity at infinite shear rate $[\mathrm{Pa}$ s] \\
\hline$\eta$ & Generalized viscosity in Carreau model $[\mathrm{Pa} \mathrm{s}]$ \\
\hline$\theta$ & Density fraction in cavitation $\mathrm{model}$ \\
\hline$\mu$ & Friction coefficient \\
\hline$\sigma$ & Normal stress [Pa] \\
\hline$\tau$ & Shear stress [Pa] \\
\hline$v$ & Poission's ratio \\
\hline$\rho_{0}$ & Ambient fluid density $\left[\mathrm{kg} / \mathrm{m}^{3}\right]$ \\
\hline$\rho$ & Generalized fluid density $\left[\mathrm{kg} / \mathrm{m}^{3}\right]$ \\
\hline$\omega$ & Rotation velocity of cylinder $[\mathrm{rad} / \mathrm{s}]$ \\
\hline
\end{tabular}

\section{REFERENCES}

[1] Segu DZ, Choi SG, Choi JH, Kim SS. The Effect of Multi-Scale Laser Textured Surface on Lubrication Regime. Appl Surf Sci. 2013;270:58-63.

[2] Braun D, Greiner C, Schneider J, Gumbsch P. Efficiency of laser surface texturing in the reduction of friction under mixed lubrication. Tribol Int. 2014;77:142-47.

[3] Ryk G, Etsion I. Testing piston rings with partial laser surface texturing for friction reduction. Wear. 2006;261:792-96.

[4] Tomanik E. Modelling the hydrodynamic support of cylinder bore and piston rings with laser textured surfaces. Tribol Int. 2013;59:90-96.

[5] Etsion I, Kligerman Y, Halperin G. Analytical and Experimental Investigation of LaserTextured Mechanical Seal Faces. Tribol Trans. 1999;42:511-16.

[6] Brunetiere N, Tournerie B. Numerical analysis of a surface-textured mechanical seal operating in mixed lubrication regime. Tribol Int. 2012;49:80-89.

[7] Dobrica MB, Fillon M, Maspeyrot P. Mixed elastohydrodynamic lubrication in a partial journal bearing-comparison between deterministic and Stochastic models. ASME J Tribol. 2006; 128:778-88.

22 [8] Rao TVVLN, Rani AMA, Nagarajan T, Hashim FM. Analysis of slider and journal bearing using partially textured slip surface. Tribol Int. 2012;56:121-28. 
[9] Dobrica MB, Fillon M, Pascovici MD, Cicone T. Optimizing surface texture for hydrodynamic lubricated contacts using a mass-conserving numerical approach. Proc Inst Mech Eng, Part J: J Eng Tribol. 2010;224:737-50.

[10] Sharma SC, Yadav SK. Performance analysis of a fully textured hybrid circular thrust pad bearing system operating with non-Newtonian lubricant. Tribol Int. 2014;77:50-64.

[11] de Boer GN, Hewson RW, Thompson HM, Gao L, Toropov VV. Two-scale EHL: 3D Topography in Slider Bearings. Tribol Int. 2014;79:111-25.

8 [12] Gao LM, Hewson R. A Multiscale Framework for EHL and Micro-EHL. Tribol Trans. 9 2012;55:713-22.

10 [13] Hao LC, Meng YG, Chen C. Experimental investigation on effects of surface texturing on 11 lubrication of initial line contacts. Lubr Sci. 2014;26:363-73.

12 [14] Janakiraman S, Klit P, Jensen NS, Gronbaek J. Observations on the effects of grooved surfaces on the interfacial torque in highly loaded rolling and sliding tests. Tribol Int. 2015;81:179-89.

[15] Marian VG, Predescu A, Pascovici MD. Theoretical analysis of an infinitely wide rigid cylinder rotating over a grooved surface in hydrodynamic conditions. Proc Inst Mech Eng, Part J: J Eng Tribol. 2010;224:757-63.

[16] Vrbka M, Krupka I, Samanek O, Svoboda P, Vaverka M, Hartl M. Effect of surface texturing on lubrication film formation and rolling contact fatigue within mixed lubricated nonconformal contacts. Meccanica. 2011;46:491-98.

[17] Wang XL, Liu W, Zhou F, Zhu D. Preliminary Investigation of the Effect of Dimple Size on Friction in Line Contacts. Tribol Int. 2009;42:1118-23.

[18] Zhu D, Nanbu T, Ren N, Yasuda Y, Wang QJ. Model-Based Virtual Surface Texturing for Concentrated Conformal-Contact Lubrication. Proc Inst Mech Eng, Part J: J Eng Tribol.

2010;224:685-96.

[19] Kaneta M, Guo F, Wang J, Krupka I, Hartl M. Formation of Micro-Grooves Under Impact Loading in Elliptical Contacts with Surface Ridges. Tribol Int. 2013;65:336-45.

[20] Mourier L, Mazuyer D, Ninove FP, Lubrecht AA. Lubrication Mechanisms with LaserSurface-Textured Surfaces in Elastohydrodynamic Regime. Proc Inst Mech Eng, Part J: J Eng Tribol. 2010;224:697-711.

[21] Minet C, Brunetiere N, Tournerie B. A Deterministic Mixed Lubrication Model for Mechanical Seals. ASME J Tribol. 2011;133.

[22] de Kraker A, Ostayen R, Beek A, Rixen D. A Multiscale Method Modelling Surface Texture Effects. ASME J Tribol. 2007;129:221-30.

[23] Demirci I, Mezghani S, Yousfi M, El Mansori M. Multiscale Analysis of the Roughness Effect on Lubricated Rough Contact. ASME J Tribol. 2014;136.

[24] Jai M, Bou-Said B. A Comparison of Homogenization and Averaging Techniques for the Treatment of Roughness in Slip-Flow-Modified Reynolds Equation. ASME J Tribol. 2002; 124:327-35.

[25] Nyemeck AP, Brunetiere N, Tournerie B. A Multiscale Approach to the Mixed Lubrication Regime: Application to Mechanical Seals. Tribol Lett. 2012;47:417-29.

[26] Sahlin F, Larsson R, Almqvist A, Lugt P, Marklund P. A Mixed Lubrication Model Incorporating Measured Surface Topography. Part 1: Theory of Flow Factors. Proc Inst Mech Eng, Part J: J Eng Tribol. 2010;224:335-51.

[27] Patir N, Cheng HS. Average Flow Model for Determining Effects of 3-Dimensional Roughness on Partial Hydrodynamic Lubrication. ASME J Lubric Tech. 1978;100:12-17. 
[28] Shen C, Khonsari MM. On the Magnitude of Cavitation Pressure of Steady-State Lubrication. Tribol Lett. 2013;51:153-60.

[29] Olver AV, T Fowell M, Spikes HA, Pegg IG. 'Inlet Suction', A Load Support Mechanism in Non-Convergent, Pocketed, Hydrodynamic Bearings. Proc Inst Mech Eng, Part J: J Eng Tribol. 2006;220:105-08.

[30] Ausas R, Ragot P, Leiva J, Jai M, Bayada G, Buscaglia GC. The Impact of the Cavitation Model in The Analysis of Microtextured Lubricated Journal Bearings. ASME J Tribol. 2007;129:868-75.

[31] Qiu Y, Khonsari MM. On the Prediction of Cavitation in Dimples Using a MassConservative Algorithm. ASME J Tribol. 2009;131:041702.

11 [32] Shi X, Ni T. Effects of Groove Textures on Fully Lubricated Sliding with Cavitation. 12 Tribol Int. 2011;44:2022-28.

13 [33] Wahl R, Schneider J, Gumbsch P. In Situ Observation of Cavitation in Crossed 14 Microchannels. Tribol Int. 2012;55:81-86.

15 [34] Meng FM, Yang T. Preliminary Study on Mechanism of Cavitation in Lubricant of 16 Textured Sliding Bearing. Proc Inst Mech Eng, Part J: J Eng Tribol. 2013;227:695-708.

17 [35] E W, Engquist B. The Heterogeneous Multi-Scale Methods. Comm in MathSci. 2003;1:8718133.

19 [36] Gao L, Hewson RW. A Multi-Scale Framework for EHL and Micro-EHL. International 20 Tribology Conference (ITC), Hiroshima, Japan, 2011.

21 [37] Green n, A.E. , Rivlin RS, Shield RT. General theory of small elastic deformations 22 superposed on large elastic deformations. Proc Roy Soc A. 1952;211:128-54. [38] Dowson D, Higginson GR. Elasto-Hydrodynamic Lubrication, the Fundamentals of Roller and Gear Lubrication: Pergamon Press, Oxford; 1966.

[39] Barus C. Isotherms, Isopiestics and Isometrics Relative to Viscosity. Am J Sci. 1893;45:8796.

[40] Bair S, Qureshi F. The Generalized Newtonian Fluid Model and Elastohydrodynamic Film Thickness. ASME J Tribol. 2003;125:70-75.

[41] Almqvist T, Larsson R. The Navier-Stokes Approach for Thermal EHL Line Contact Solutions. Tribol Int. 2002;35:163-70.

[42] Habchi W, Vergne P, Bair S, Andersson O, Eyheramendy D, Morales-Espejel GE.

Influence of Pressure and Temperature Dependence of Thermal Properties of a Lubricant on the Behaviour of Circular TEHD Contacts. Tribol Int. 2010;43:1842-50.

[43] Dorf RC. The Engineering Handbook. US: CRC Press; 2005.

[44] Barber C, Dobkin D, Huhdanpaa H. The Quickhull algorithm for convex hulls. ACM Trans on Math Soft. 1996;22:469-83.

[45] Krupka I, Hartl M. The Effect of Surface Texturing on Thin EHD Lubrication Films. Tribol Int. 2007;40:1100-10. 


\section{Tables and Figures}

2

3 Table 1 Geometrical and material parameters

4 Table 2 Fluid Properties

5 Table 3 Date selection of small scale simulations

6 unit cell on the stationary wall surface

Fig. 2 Shear-thinning and piezo-viscous fluid property function (d) scale geometry minimum film thickness) minimum film thickness) location of the minimum film thickness)

Fig. 1 (a) Global geometry of a cylinder bearing in line contact, (b) micro pocket geometry of a

Fig. 3 Variations of the density fraction against fluid pressure described by hyperbolic tangent

Fig. 4 Mesh sensitivity analysis on smooth surface: (a) relative errors in the large-scale pressure and mass flow rate using the solution of the finest mesh (960) as reference, (b) the large-scale pressure distributions, and (c) enlarged local pressure details of figure (b)

Fig. 5 Friction coefficient against ratio $(d / L)$ and the minimum film thickness against cell depth

Fig. 6 Newtonian solutions: (a) pressure and density fraction, (b) film thickness (textured surface with optimal parameters compared to smooth surface), (c) small scale pressure and (d) density fraction variations at different locations convergent zone $X=[0.85,1.9]$ in the large

Fig. 7 Piezo-viscous solutions: (a) pressure and viscosity, (b) film thickness (textured surface with optimal parameters compared to smooth surface; the arrow shows location of the

Fig. 8 Shear-thinning solutions: (a) pressure and viscosity, (b) film thickness (textured surface with optimal parameters compared to smooth surface; the arrow shows location of the

Fig. 9 Shear-thinning and piezo-viscous solutions: (a) pressure and viscosity, (b) film thickness (textured surface with optimal parameters compared to smooth surface; the arrow shows 
1

2

3

4

5

6

7

8

9

10

11

12

Table 1 Geometrical and material parameters

\begin{tabular}{|l|l|}
\hline Cylinder radius & $r=25 \mathrm{~mm}$ \\
\hline Micro pocket length & $L=20 \mu \mathrm{m}-200 \mu \mathrm{m}$ \\
\hline Micro pocket depth & $d=5 \mu \mathrm{m}-30 \mu \mathrm{m}$ \\
\hline Young's modulus of PTFE & $E=0.5 \mathrm{GPa}$ \\
\hline Poisson's ratio of PTFE & $v=0.4$ \\
\hline Sliding speed of smooth surface & $\mathrm{u}=2 \mathrm{~m} / \mathrm{s}$ \\
\hline
\end{tabular}

Table 2 Fluid Properties

\begin{tabular}{|l|l|}
\hline Ambient pressure & $p_{a}=10^{5} \mathrm{~Pa}$ \\
\hline Ambient fluid density & $\rho_{0}=870 \mathrm{~kg} / \mathrm{m}^{3}$ \\
\hline Viscosity at zero shear rate & $\eta_{0}=0.01 \mathrm{Pas}$ \\
\hline Viscosity at infinite shear rate & $\eta_{\infty}=0.006 \mathrm{Pas}$ \\
\hline Density-pressure coefficient & $\begin{array}{l}c_{1}=5.9 \times 10^{8} \mathrm{~Pa} \\
c_{2}=1.34\end{array}$ \\
\hline Pressure-viscosity coefficient & $\alpha$ \\
$=2.2 \times 10^{-8} \mathrm{~Pa}^{-1}$ \\
\hline Critical stress at ambient pressure & $G_{c r}=2 \times 10^{4} \mathrm{~Pa}$ \\
\hline Power in Carreau viscosity model & $m=0.6$ \\
\hline Constants in cavitation model & $\begin{array}{l}k_{1}=5 \\
k_{2}=1.5 \times 10^{5} \mathrm{~Pa}\end{array}$ \\
\hline
\end{tabular}

Table 3 Date selection of small scale simulations

\begin{tabular}{|c|c|c|}
\hline & Range & $\begin{array}{c}\text { Number of } \\
\text { mesh point }\end{array}$ \\
\hline Gap & $1-55 \mu \mathrm{m}$ & 30 \\
\hline Pressure gradient & $-2 \mathrm{e} 10-2 \mathrm{e} 10\left(\mathrm{~N} / \mathrm{m}^{\wedge} 3\right)$ & 10 \\
\hline Cell inlet pressure & $-0.2-4(\mathrm{MPa})$ & 10 \\
\hline
\end{tabular}

(1) 


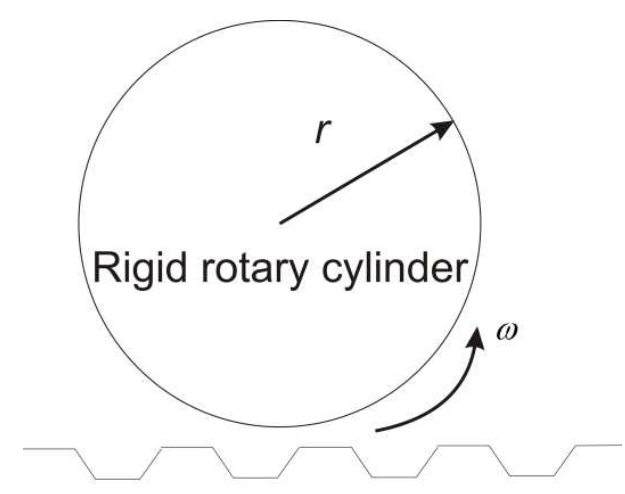

(a) Pocketed stationary wall (b)

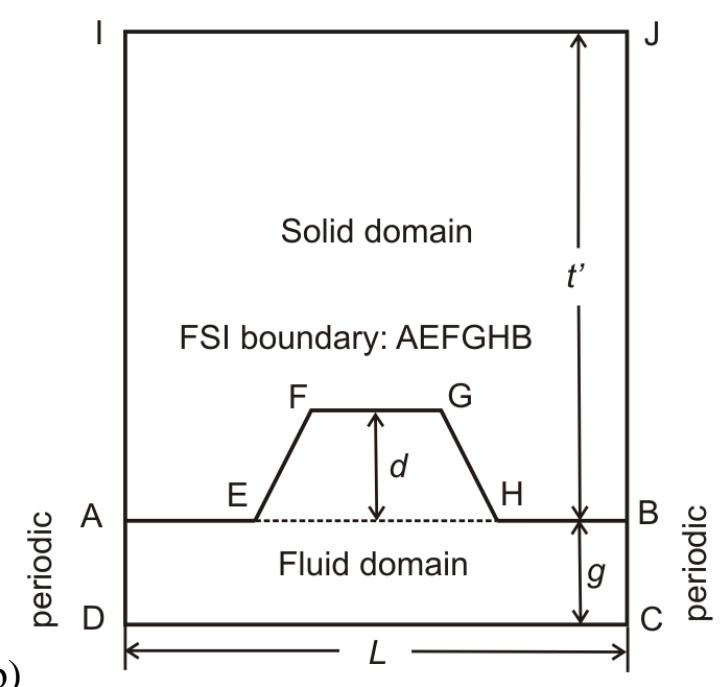

5

Fig. 1 (a) Global geometry of a cylinder bearing in line contact, (b) micro pocket geometry of a 6 unit cell on the stationary wall surface (side length $|\mathrm{AE}|=|\mathrm{FG}|=|\mathrm{HB}|=L / 5,|\mathrm{EF}|=|\mathrm{GH}|=$ 7 $\left.\sqrt{(L / 5)^{2}+d^{2}}.\right)$

8

9

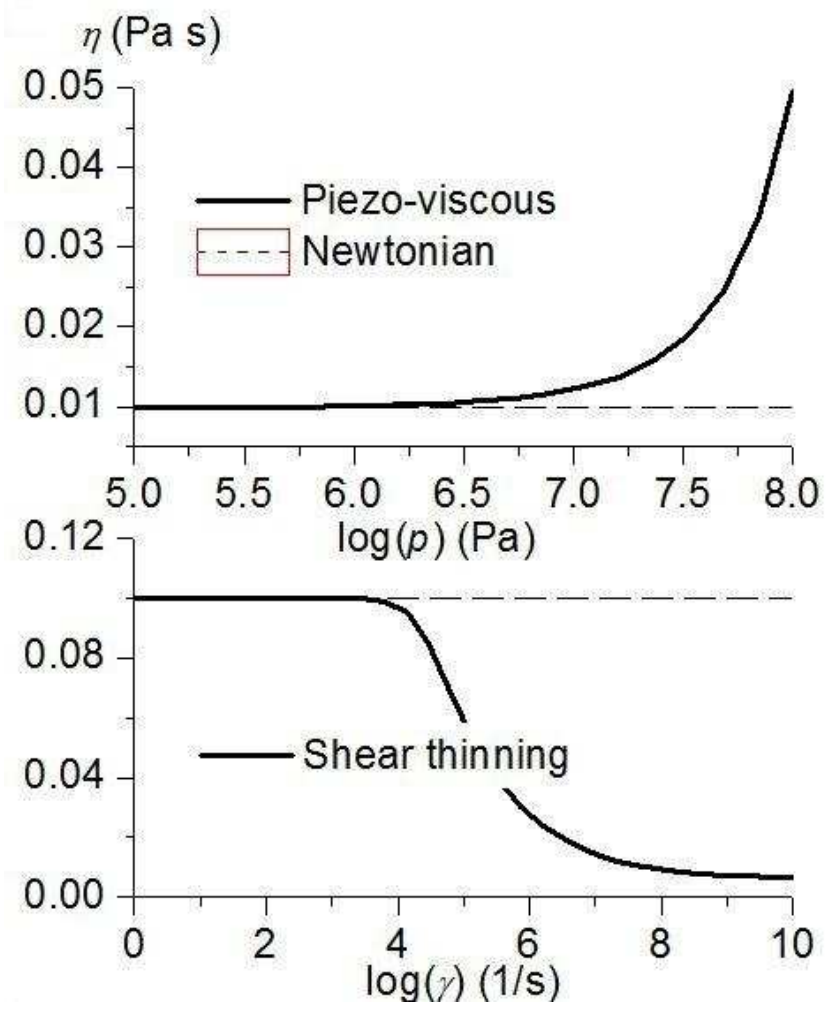


4
Fig. 2 Shear-thinning and piezo-viscous fluid property

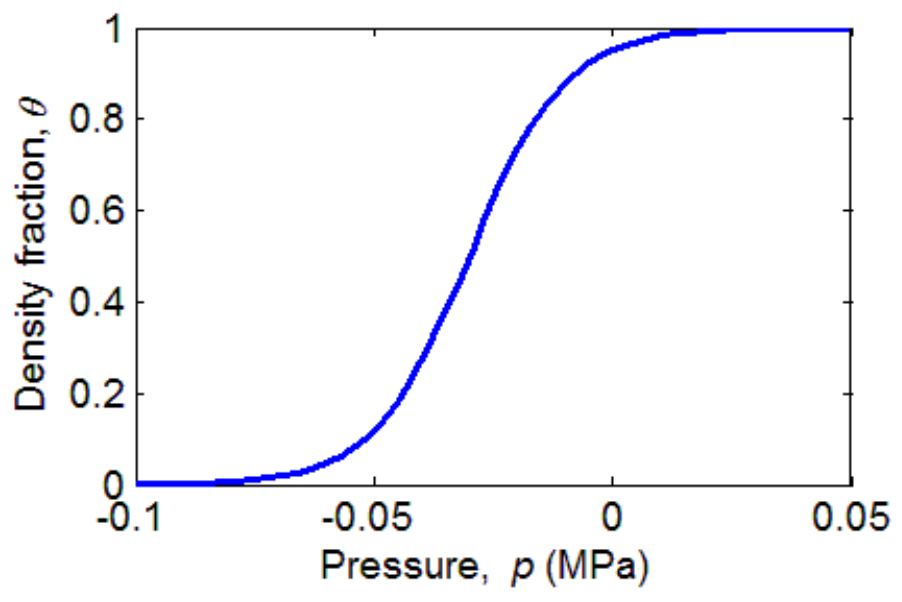

Fig. 3 Variations of the density fraction against fluid pressure described by hyperbolic tangent function 

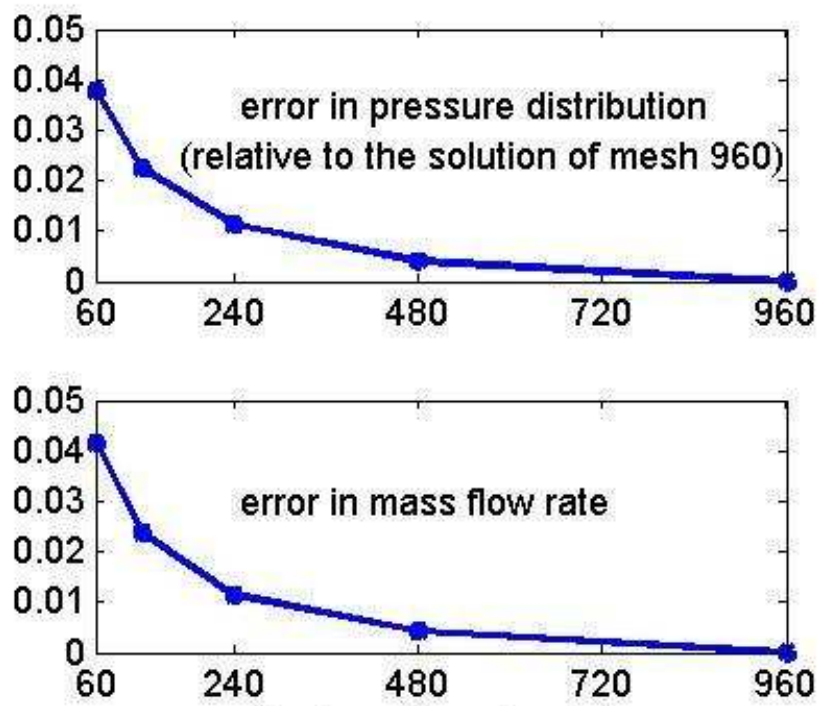

(a)

Number of mesh points

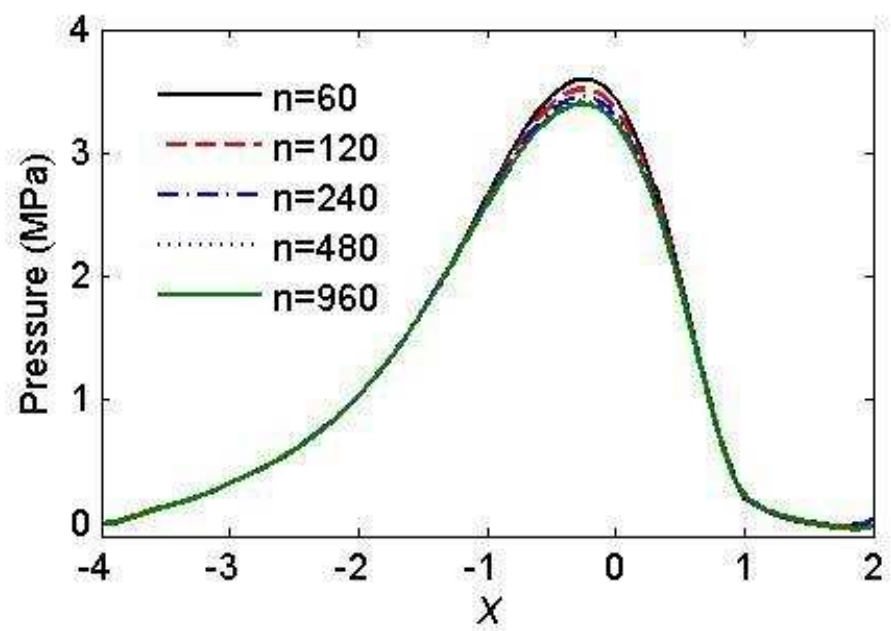

(b)

(c)

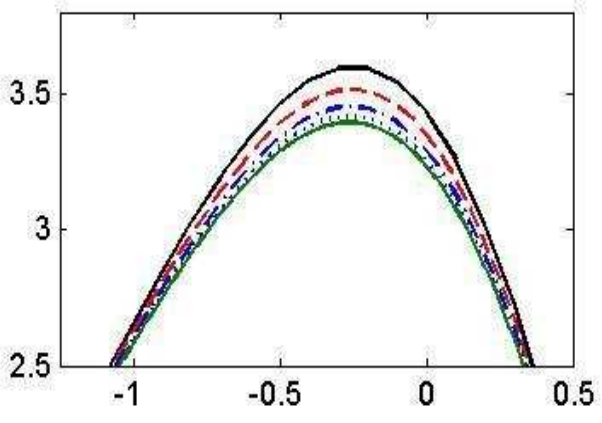


1 Fig. 4 Mesh sensitivity analysis on smooth surface: (a) relative errors in the large-scale pressure 2 and mass flow rate using the solution of the finest mesh (960) as reference, (b) the large-scale 3 pressure distributions, and (c) enlarged local pressure details of figure (b) 


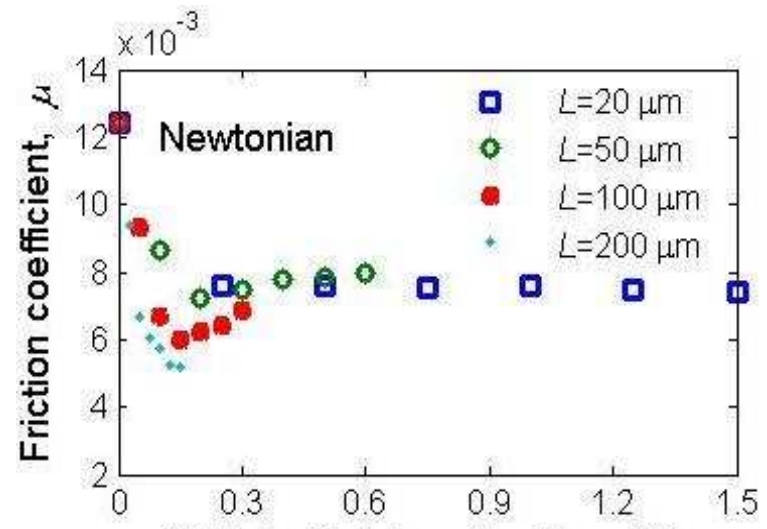

a) Cell depth to length ratio, $d / L$

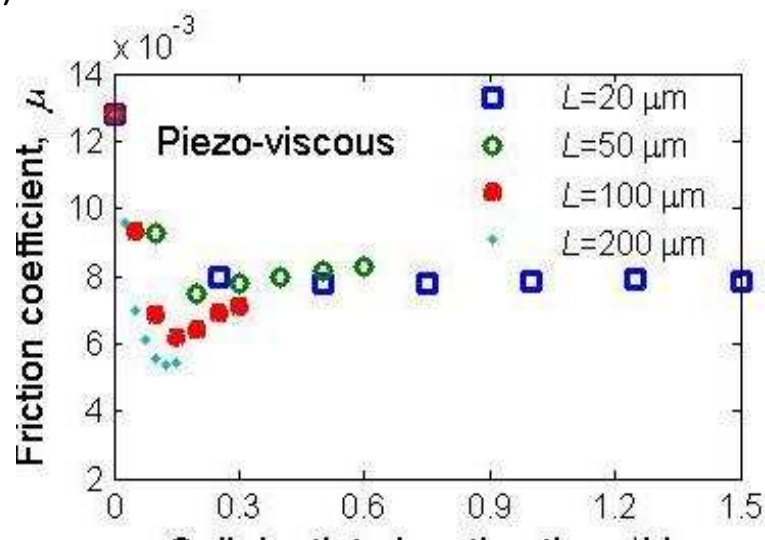

2 b)

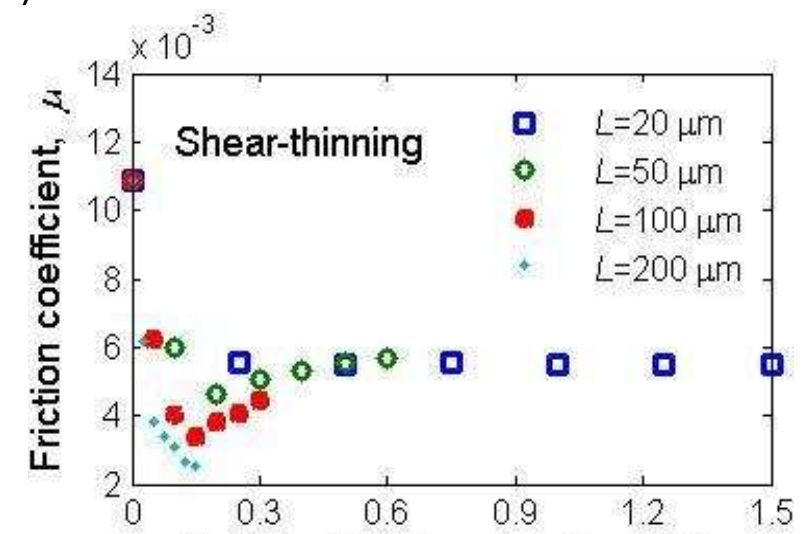

3 c)

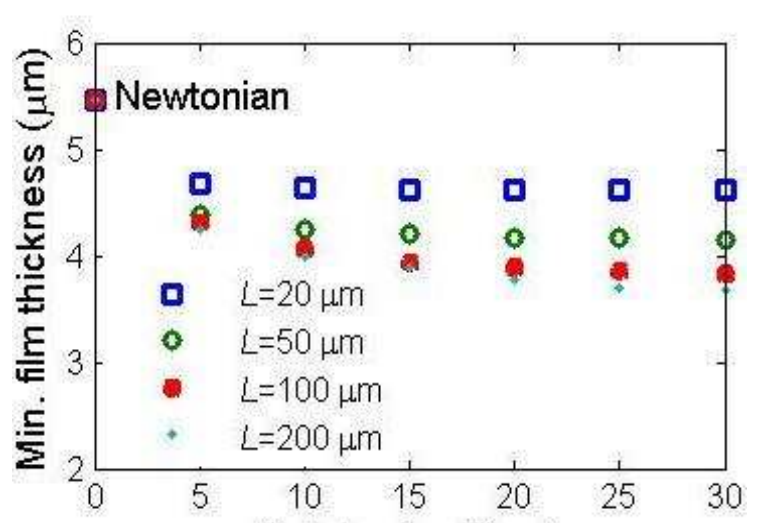

Cell depth, $d(\mu \mathrm{m})$

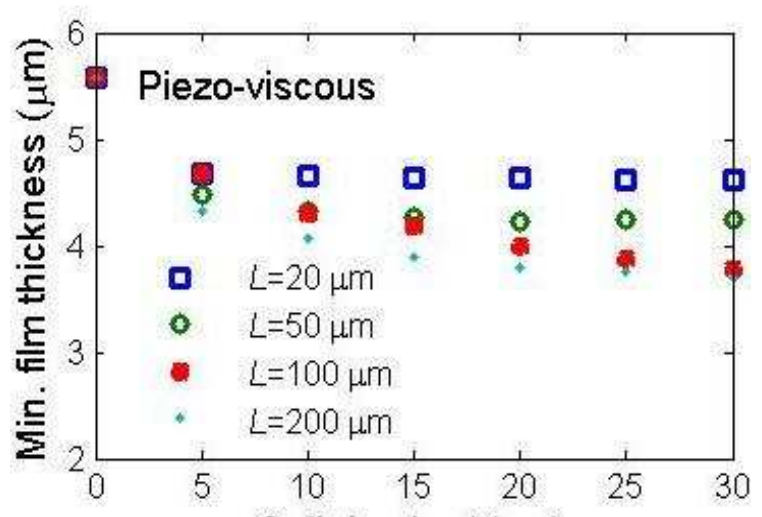

Cell depth, $d(\mu \mathrm{m})$

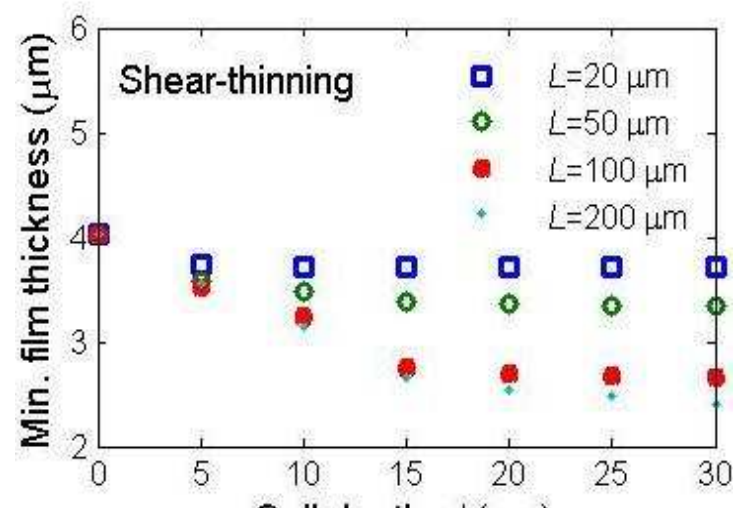

Cell depth, $d(\mu \mathrm{m})$ 


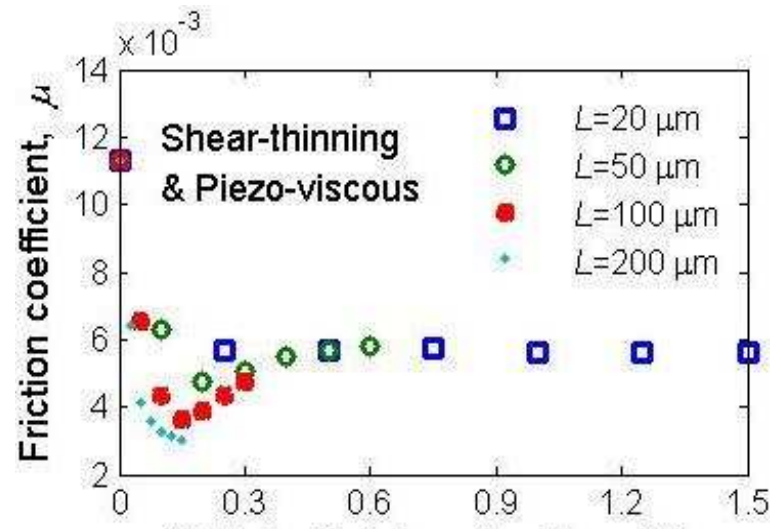

d)

Cell depth to length ratio, $d / L$

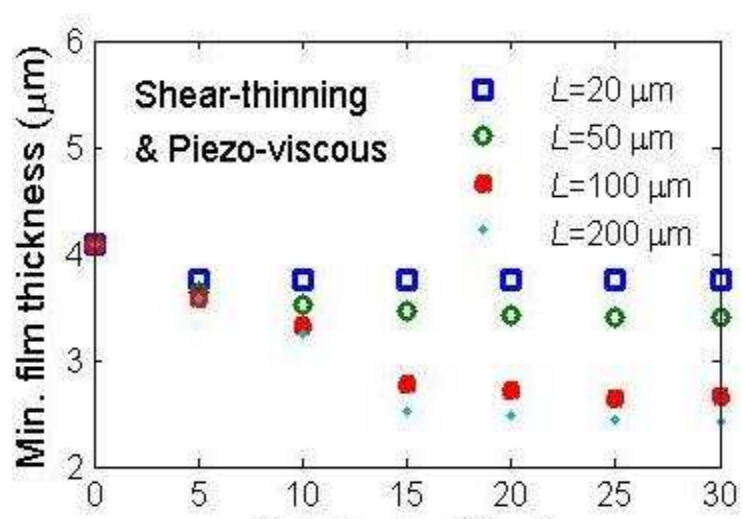

Cell depth, $d(\mu \mathrm{m})$

2 Fig. 5 Friction coefficient against ratio $(d / L)$ (left) and the minimum film thickness against cell

3 depth (d) (right); a) Newtonian; b) Peizo-viscous; c) Shear-thinning; d) Shear-thinning \& Piezo-

4 viscous

5

6

7

8 
1 a)

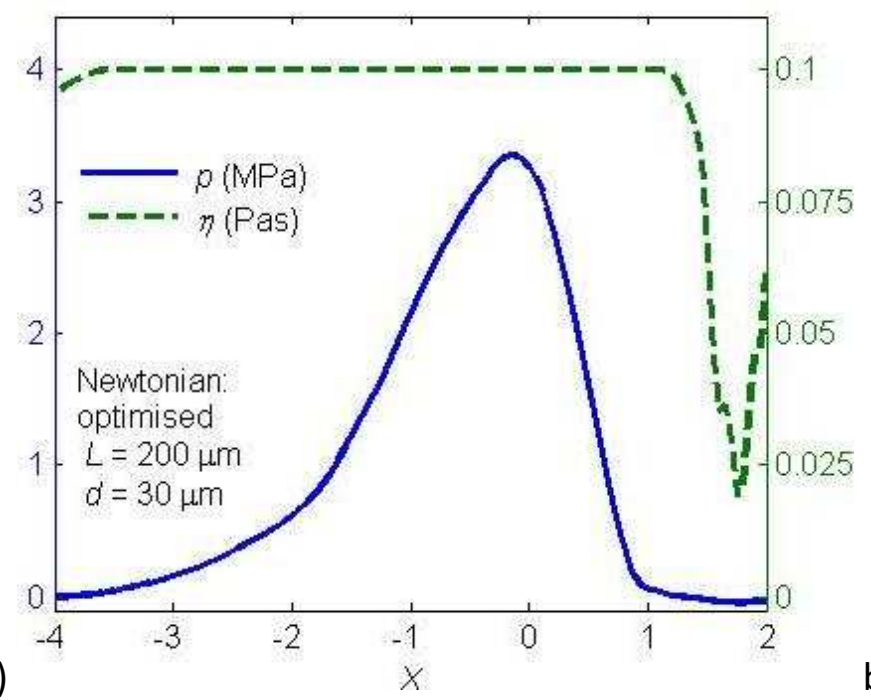

b)

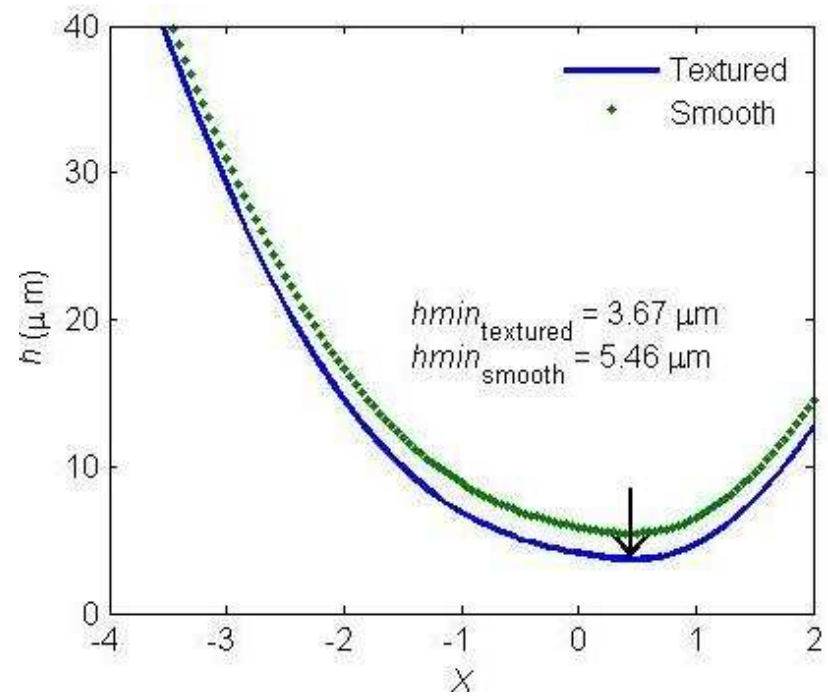

2
3 


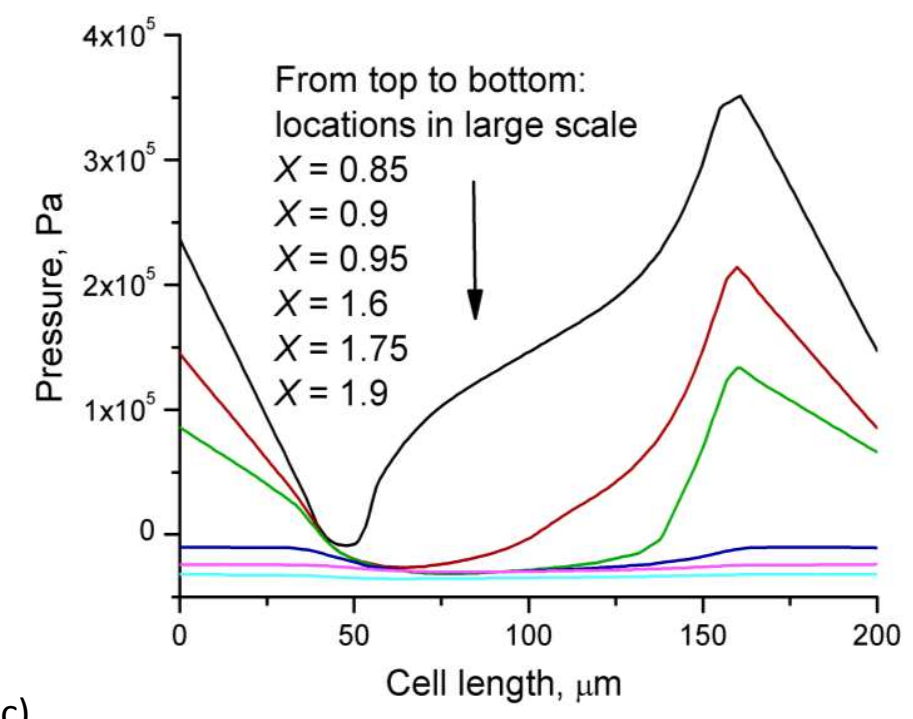

c)

d)

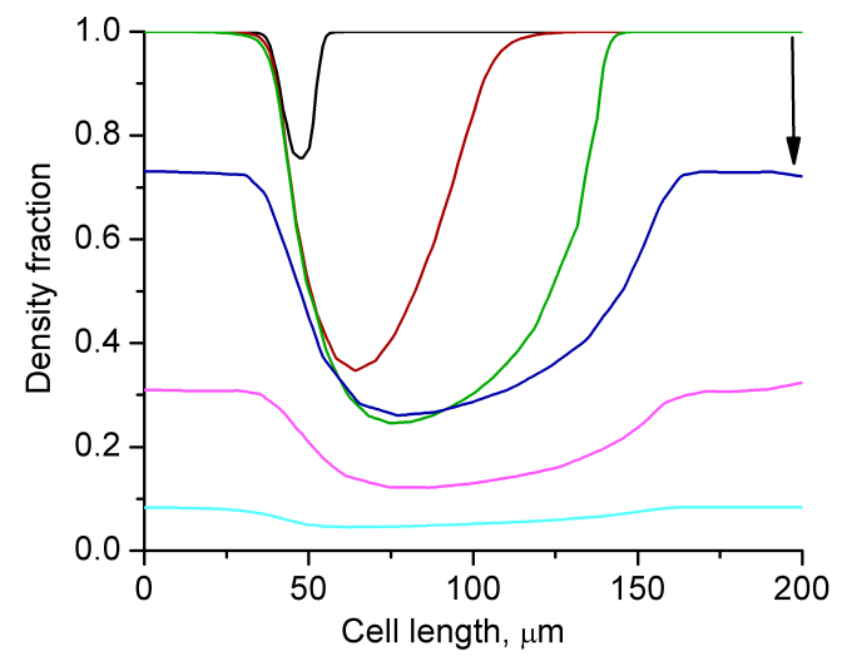

Fig. 6 Newtonian solutions: (a) pressure and viscosity fraction, (b) film thickness (textured surface with optimal parameters compared to smooth surface), (c) small scale pressure and (d) density fraction variations at different locations convergent zone $X=[0.85,1.9]$ in the large scale geometry 


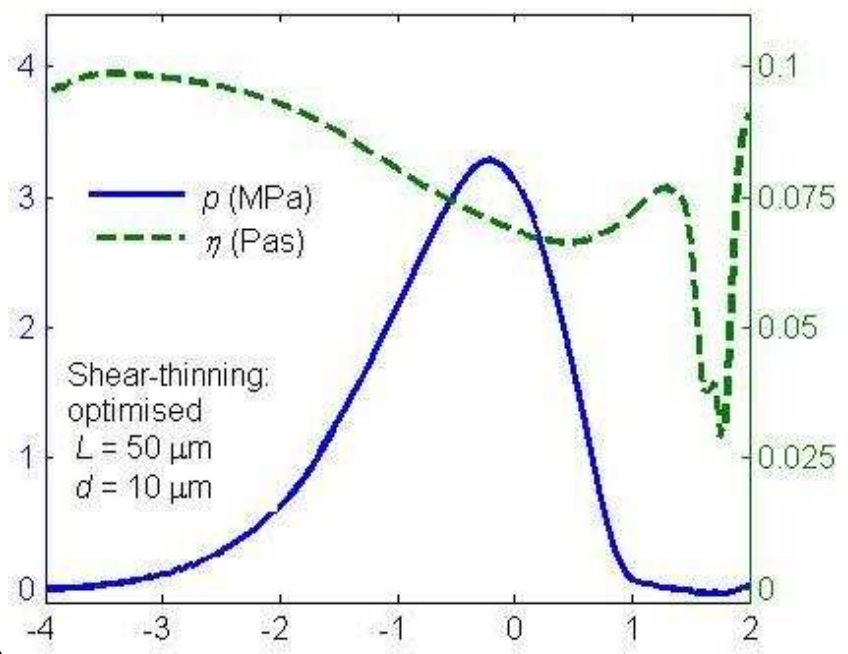

a)

$x$

b)

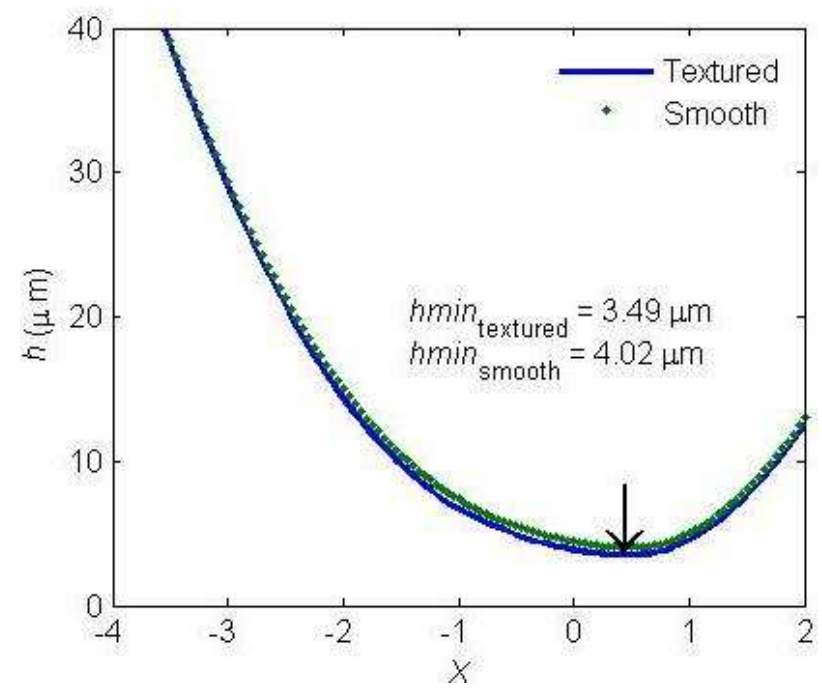

4

Fig. 7 Shear-thinning solutions: (a) pressure and viscosity, (b) film thickness (textured surface with optimal parameters compared to smooth surface; the arrow shows location of the minimum film thickness) 

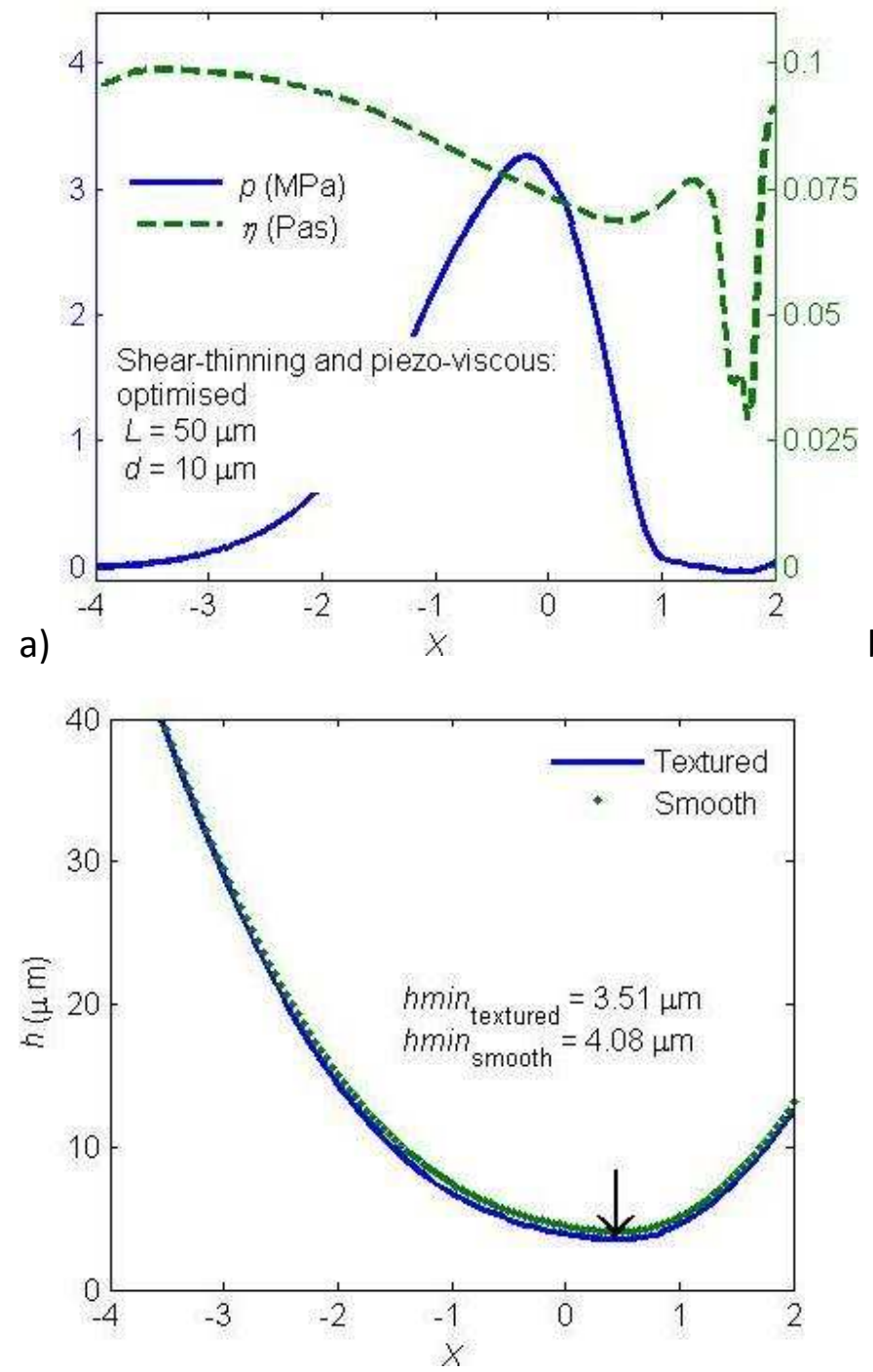

3 Fig. 8 Shear-thinning and piezo-viscous solutions: (a) pressure and viscosity, (b) film thickness 4 (textured surface with optimal parameters compared to smooth surface; the arrow shows 5 location of the minimum film thickness) 